\title{
Revisão de pesquisas em design de origami na área médica
}

\section{Review of origami design researches in medical field}

\author{
Samanta Aline Teixeira, UNESP - Universidade Estadual Paulista \\ samanta.teixeira@unesp.br
}
Galdenoro Botura Junior, UNESP - Universidade Estadual Paulista
galdenoro.botura@unesp.br

Thaís Regina Ueno Yamada, UNESP - Universidade Estadual Paulista

thais.ueno@unesp.br

\section{Resumo}

$\mathrm{O}$ origami é uma arte japonesa que consiste em modificar uma folha plana de papel em figuras bi ou tridimensionais apenas com dobras. No momento atual essa arte está sendo incorporada em diversas tecnologias na área do design de produtos, arquitetura, moda, engenharia espacial e ciência de materiais, mas é na área médica que o origami está ganhando especial atenção dos pesquisadores, pois seus métodos de design têm apresentado interessantes inovações em soluções de formas e estruturas. O presente artigo é uma revisão sobre design de origami aplicado à área médica, analisando as características de algumas pesquisas aplicadas, como os tipos de materiais, processos de fabricação, as necessidades e demandas de cada área da saúde, e quais são as vantagens estratégicas das dobraduras em termos de melhorias nos custos, processos de manufatura, usabilidade, e sustentabilidade.

Palavras-chave: Design de origami, Medicina, Multidisciplinaridade, Inovação, Métodos em Design.

\begin{abstract}
Origami is a Japanese art that consists of modifying a flat sheet of paper in two or threedimensional figures only by folding. At the present this art is being incorporated into several technologies in the area of product design, architecture, fashion, space engineering and materials science, but it is in the medical field that origami is gaining special attention from researchers, as its design methods have presented interesting innovations in solutions of shapes and structures. This article is a review of origami design applied to the medical field, analyzing the characteristics of some applied researches, such as the types of materials, manufacturing processes, the needs and demands of each area of health, and what are the strategic advantages of folding in terms of improvements in costs, manufacturing processes, usability, and sustainability.
\end{abstract}

Keywords: Origami Design, Medicine, Multidisciplinary, Innovation, Design Methods. 


\section{Introdução}

O origami é uma arte oriental ancestral que transforma o papel plano em diferentes formatos simples ou complexos por meio de dobras. A complexidade histórica das dobraduras japonesas refletiu em sua linguagem e estética e proporcionou técnicas práticas e de fácil acesso, trazendo em evidência uma complexidade geométrica e forte tendência à multidisciplinaridade e inovação. É possível observar dois tipos distintos de metodologias em design de origami, a inspiração e a adaptação (FRANCIS et al., 2014). O design inspirado no origami (KUZUYA et al., 2011) tem enfoque no raciocínio das dobras, ou seja, investigando e aplicando o funcionamento do origami enquanto paradigma de uma forma subjetiva, sendo que esta área possui pesquisas aplicadas em microbiologia, farmacologia, bioquímica, biologia molecular, e genética. O design de adaptação do origami (CHEN; PENG; YOU, 2015) se orienta pelos mecanismos das dobras, quer dizer, pesquisando e projetando o origami como objeto ou estrutura, tendo esta área pesquisas de maior enfoque no funcionalismo e criatividade dentro das ciências sociais aplicadas, como o design de produtos, engenharia de materiais e tecnologias na área da astronomia.

\begin{tabular}{|c|c|c|}
\hline $\begin{array}{c}\text { TIPO DE PESQUISA EM } \\
\text { DESIGN DE ORIGAMI }\end{array}$ & Inspiração & Adaptação \\
\hline EXEMPLO DE PESQUISA & Kuzuya et al., 2011 & Chen, Peng e You, 2015 \\
\hline FORMA ASSOCIADA & Abstrata, subjetiva & Concreta, objetiva \\
\hline ESTRATÉGIA TÉCNICA & Raciocínio das dobras & Mecanismo das dobras \\
\hline ÁREAS DE ATUAÇÃO & $\begin{array}{r}\text { Biologia molecular, } \\
\text { nanotecnologia, bioquímica, } \\
\text { ciências de materiais, } \\
\text { multidisciplinaridades }\end{array}$ & $\begin{array}{c}\text { Engenharias, robótica, } \\
\text { ciências tecnológicas, } \\
\text { ciências de materiais, } \\
\text { multidisciplinaridades }\end{array}$ \\
\hline
\end{tabular}

Figura 1: Os tipos de design de origami e suas características. Fonte: Elaborada pelos autores. 
No entanto, existem as áreas multidisciplinares que transitam por ambos os segmentos de inspiração e adaptação, ou seja, são domínios que se preocupam tanto com o raciocínio quanto com o mecanismo das dobras: é o caso da matemática, ciências da computação, nanotecnologia, ciências de materiais e medicina. O design de origami para desenvolvimento de produtos na área da saúde pode agregar uma série de vantagens como a diminuição de custos de manufatura, simplificação de forma, diminuição de uso de matéria-prima, eliminação de peças adjacentes e/ou sobressalentes como parafusos e dobradiças, e ter ainda a possibilidade de se obter funções multitarefas (JOHNSON et al., 2017; MERALI, 2011). A modificação de formas mais expandidas para mais compactas é especialmente interessante em ambientes cirúrgicos, onde há uma necessidade das ferramentas serem compactas para viabilizar cirurgias minimamente invasivas e facilitar a esterilização (GREENBERG et al., 2011). Além da otimização de fabricação automatizada e melhorias nas formas e funções dos artefatos médicos, o design de origami surge também com o escopo de melhorar a experiência do usuário/médica(o), facilitando o uso dos instrumentais, e para a(o)paciente, com processos cirúrgicos ou ambulatoriais mais eficazes e menos invasivos.

\begin{tabular}{|c|c|c|c|}
\hline PESQUISA & E ORIGAMI & TIPO E ÁREAS & FUNÇÕES E VANTAGENS \\
\hline $\begin{array}{l}\text { Rothemund, } \\
2006\end{array}$ & 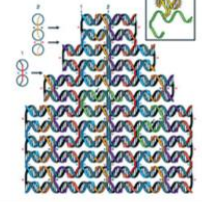 & $\begin{array}{l}\text { Inspiração } \\
\text { Biologia } \\
\text { Molecular }\end{array}$ & $\begin{array}{l}\text { - Técnica de compactação do } \\
\text { material genético; } \\
\text { - Melhorias em estequiometria e } \\
\text { purificação. }\end{array}$ \\
\hline $\begin{array}{l}\text { Veneziano } \\
\text { et al., } \\
2020\end{array}$ & & $\begin{array}{c}\text { Inspiração } \\
\text { Ciências de } \\
\text { Materiais, } \\
\text { Nanotecnologia }\end{array}$ & $\begin{array}{l}\text { - Estruturas proteicas que } \\
\text { simulam vírus; } \\
\text { - Respostas imunológicas para } \\
\text { produção de vacinas. }\end{array}$ \\
\hline $\begin{array}{l}\text { Kuribayashi } \\
\text { et al., } \\
2006\end{array}$ & & $\begin{array}{c}\text { Adaptação } \\
\text { Ciências de } \\
\text { Materiais, } \\
\text { Nanotecnologia }\end{array}$ & $\begin{array}{l}\text { - Stent cardíaco para cirurgia de } \\
\text { angioplastia; } \\
\text { - Peça monolítica, economia de } \\
\text { matéria-prima, montagens e } \\
\text { custos. }\end{array}$ \\
\hline $\begin{array}{c}\text { Li et al., } \\
2017\end{array}$ & & $\begin{array}{c}\text { Adaptação } \\
\text { Ciências e } \\
\text { Tecnologia, } \\
\text { Multidisciplinar }\end{array}$ & $\begin{array}{l}\text { - Músculo artificial acionado por } \\
\text { fluido; } \\
\text { - Levanta cargas e recupera } \\
\text { movimentos corporais, design } \\
\text { possibilita diversos processos } \\
\text { fabris. }\end{array}$ \\
\hline $\begin{array}{l}\text { Miyashita } \\
\text { et al., } \\
2016\end{array}$ & & $\begin{array}{l}\text { Adaptação } \\
\text { Automação, } \\
\text { Robótica }\end{array}$ & $\begin{array}{l}\text { - Microrrobô multitarefa para } \\
\text { estômago; } \\
\text { - Se adapta em pequenos } \\
\text { espaços, costura feridas, remove } \\
\text { corpos estranhos e entrega } \\
\text { medicamentos. }\end{array}$ \\
\hline $\begin{array}{l}\text { Edmondson } \\
\text { et al., } \\
2013\end{array}$ & & $\begin{array}{l}\text { Adaptação } \\
\text { Automação, } \\
\text { Ciências de } \\
\text { Materiais }\end{array}$ & $\begin{array}{l}\text { - Pinça para cirurgia de } \\
\text { laparoscopia; } \\
\text { - Estudos de forma em papel } \\
\text { rápidos e baratos; } \\
\text { - Peça monolítica, economia de } \\
\text { matéria-prima, montagens e } \\
\text { custos. }\end{array}$ \\
\hline
\end{tabular}

Figura 2: Principais pesquisas de design de origami na área médica. Fonte: Elaborada pelos autores. 
São diversos os dispositivos voltados à saúde humana projetados a partir de design de origami e que possuem atuação em diferentes ramos como a angioplastia, radiologia, gastroenterologia, e em tratamentos diversos, podendo ser endopróteses (KURIBAYASHI et al., 2006), robôs em miniatura para microcirurgias e intervenções clínicas (MIYASHITA et al., 2014, 2015, 2016), micropinças cirúrgicas (BASSIK et al., 2010; EDMONDSON et al., 2013), ataduras terapêuticas (ZHAO et al., 2018), cateterismo cardíaco (CHEN et al., 2015; SCHMIDT et al., 2011; TAYLOR et al., 2016), e mesmo administração de medicamentos mais eficazes (ZHU; LI, 2014). O artigo propõe uma revisão e análise de pesquisas que se baseiam nas metodologias projetuais das dobraduras para a área médica, com intuito de entender melhor como são as características dessas tecnologias, desde materiais, processos, formas e funções, e quais são as vantagens estratégicas de cada uma delas sob a ótica do design de origami. As possibilidades de atuação multidisciplinar e soluções inovativas são discutidas.

\section{DNA Origami}

O design do origami que parte da inspiração não compõe uma conexão direta com as dobraduras, quer dizer, é um tipo de design que não se assemelha visualmente a uma dobradura, mas que assume seus princípios de ação em dobras. Apesar do caráter subjetivo, a inspiração no origami possui estratégias de projeção bem concretas como a aplicação de dobras em estruturas orgânicas do ácido desoxirribonucleico DNA e cadeias proteicas. Paul Rothemund (2006) foi um dos primeiros a explorar e inserir o raciocínio das dobraduras à biologia molecular, conseguindo desenvolver técnicas de dobras em cadeias do DNA. Essas dobras proporcionaram que as muitas informações contidas no material genético estivessem ainda mais compactas e com uma organização inédita, tendo o pesquisador total controle de que formatos as cadeias podiam ter, desde o desenho de uma estrela, até rostos felizes de emoticons. Enquanto o DNA comum é uma cadeia gigante de informações embaralhadas, o DNA origami de Rothemund tem uma organização estrutural que não se restringe a desenhos visuais, mas que pode evitar problemas químicos importantes como a estequiometria e purificação. A inovação da pesquisa do DNA origami possibilitou que diversos outros pesquisadores dessem continuidade a novas aplicações e descobertas na genética e biologia molecular como Iwaki et al. (2016), que utilizaram o DNA origami para desenvolver uma nanomáquina biológica mecanossensível em formato de mola capaz de influenciar forças mecânicas de diversas células humanas como o crescimento e a morte celular. A pesquisa recente de Veneziano et al. (2020) utilizou a técnica de DNA Origami para projetar estruturas de proteínas espacialmente parecidas com vírus do HIV, sendo aplicadas em vacinas e que ativaram as células B, produzindo assim anticorpos que combatem a doença. Os pesquisadores acreditam que é possível utilizar o mesmo tipo de técnica em vacinas para o vírus da Zika e o SARS-CoV-2, o Coronavírus. O DNA Origami certamente é uma técnica de design de nanodispositivos com grande potencial de desenvolvimento de inovações que podem salvar vidas e melhorar processos de curas em novos medicamentos ou mesmo nos já existentes.

Há outros métodos de inspiração do origami dentro da microbiologia como a engenharia de tecidos biológicos para o fígado desenvolvida por Mehner et al. (2015). Cada tecido do corpo 
humano tem uma estrutura única e devido a isso os métodos de design de inspiração no origami são promissores pois conseguem modificar as formas estruturais por meio de dobras, possibilitando diversidade de formas e tecidos diferenciados. Por meio de amostragem de células do fígado, simulações com os softwares Abaqus ${ }^{\circledR}$ e ANSYS Parametric Design Language ${ }^{\circledR}$, e técnicas de microfabricação, os pesquisadores conseguiram um tecido que se autodobra por hidrólise utilizando dispositivos scaffold de origami, isto é, estruturas tridimensionais com partes porosas que promovem a proliferação celular. A seguir, cabe analisar como se dão os projetos de instrumentais médicos dentro do design de adaptação do origami, cujas metodologias são essencialmente distintas do design de inspiração no origami e que possuem soluções muito particulares de cada área a eles atrelada.

\section{Articulações em dobras adaptáveis para instrumental cirúrgico}

Em uma cirurgia é preciso seguir alguns parâmetros pré-estabelecidos para viabilizar a eficácia do procedimento. Essa eficácia pode ter a ver com uma esterilização bem executada, maior facilidade de fabricação dos instrumentais e melhora na qualidade de recuperação da(o) paciente. Para alcançar esses parâmetros, os processos cirúrgicos precisam ser minimamente invasivos, uma vez que quanto maiores os cortes, mais expostas ficam as partes internas do corpo e, por consequência, maiores são os riscos de infecções, hemorragias, cicatrizes aparentes, sequelas, recuperação lenta e dores prolongadas. Para viabilizar cirurgias minimamente invasivas, as ferramentas precisam ser as menores possíveis. Dentro das diferentes premissas do design de origami está a ação de modificar formas do estado planificado (ação de entrada) para o estado montado (ação de saída) de maneira simples e rápida. Desse princípio surgiram pesquisas aplicadas em Mecanismos de Lâminas Emergentes Multicamadas MLEMs (em inglês multi-layer lamina emergent mechanisms). Os MLEMs são um tipo de design de origami que possui a potencial melhoria de instrumentos cirúrgicos, pois há uma substituição de juntas e pinos dos instrumentos tradicionais para articulações em dobras adaptáveis e que se montam a partir de uma única peça planificada. Desenvolvido a partir dos MLEMs, o Oriceps (EDMONDSON et al., 2013) surgiu como pesquisa para um novo design de fórceps, isto é, um instrumento de mão em formato de pinça com articulações para laparoscopia, uma intervenção cirúrgica minimamente invasiva no aparelho digestivo, como a retirada de vesícula biliar; na ginecologia, com a retirada de cistos em ovário e útero; e na urologia, com a retirada de pedras no rim.

Levantando relevantes critérios para o novo design de pinça cirúrgica como a capacidade de força, amplitude de movimento, reutilização, descartabilidade, ângulo de fixação, custo e manufatura, o Oriceps foi projetado a partir do origami Chomper, design de Jeremy Shafer, contribuindo teórica e experimentalmente não apenas para a área das tecnologias em origami, mas também para elaboração de metodologias em design de instrumentos médicos. Os pesquisadores desenvolveram uma série de estudos de formas aplicadas no papel com quatro objetivos de design: vantagem mecânica, adequação do material, rigidez do mecanismo e escalabilidade do produto. Tendo esses objetivos em foco sob a perspectiva de análise 
quantitativa, a próxima etapa do processo de criação foi a escolha dos melhores modelos de papel com os seguintes critérios de comparação:

1. Dobradura Planificável;

2. Fabricação;

3. Número de DOFs;

4. Vantagem mecânica;

5. Atuação;

6. Superfície e tamanho;

7. Amplitude de movimento.

O primeiro critério diz respeito aos modelos serem ou não dobraduras planificáveis (do inglês flat foldable). Esse termo, intimamente associado ao conceito de MLEMs, significa que a estrutura dobrável tem a capacidade de se achatar por completo quando não está em uso (YAMADA, 2016). A dobradura planificável garante que o design seja monolítico, isto é, montado a partir de uma única folha ou bloco de material, característica esta que se conecta diretamente com o segundo critério, que é o da fabricação, pois uma vez que o modelo em origami seja planificado, ele consegue eliminar peças adjacentes e etapas de montagem das mesmas.

O terceiro critério é o número de DOFs, isto é, os graus de liberdade de movimento (do inglês degrees of freedom). O DOF é um número de parâmetros independentes que definem a posição de um corpo no espaço em qualquer instante, podendo ser um movimento de rotação, translação ou uma união dos dois, no chamado movimento complexo, por meio de juntas que podem ser cilíndricas, rotacionais, esféricas ou prismáticas (BECKER, 2014). Contudo, as juntas possuem configurações específicas quando são pensadas para design de origami e elas modificam especificamente os vincos dos modelos em papel.

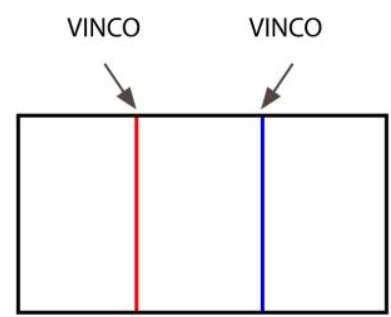

ORIGAMI PLANIFICADO

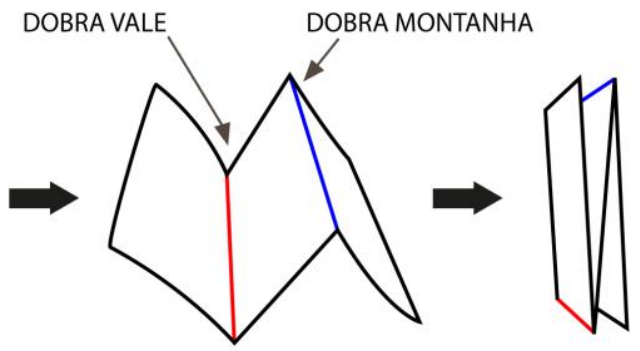

ORIGAMI DOBRADO

Figura 3: Princípio de funcionamento dos vincos no origami. Fonte: Elaborada pelos autores.

Os vincos são juntas de dobradiças rotativas formadas a partir da deformação do material, sendo um recurso linear onde ocorrem as dobras (AVILA et al., 2019). Os planos do papel giram para cima para formar uma dobra vale e giram para baixo para formar uma dobra montanha (DUREISSEIX, 2012), como esquematizado na figura 3. Se o modelo de origami é transposto do papel para outros tipos de materiais mais rígidos, adaptações são necessárias no 
local dos vincos para que a cinemática e a geometria estrutural se preservem. Na figura 4, Morgan et al. (2016) fazem uma reunião dos principais designs que transpõem os vincos do papel para juntas adaptativas em materiais rígidos.

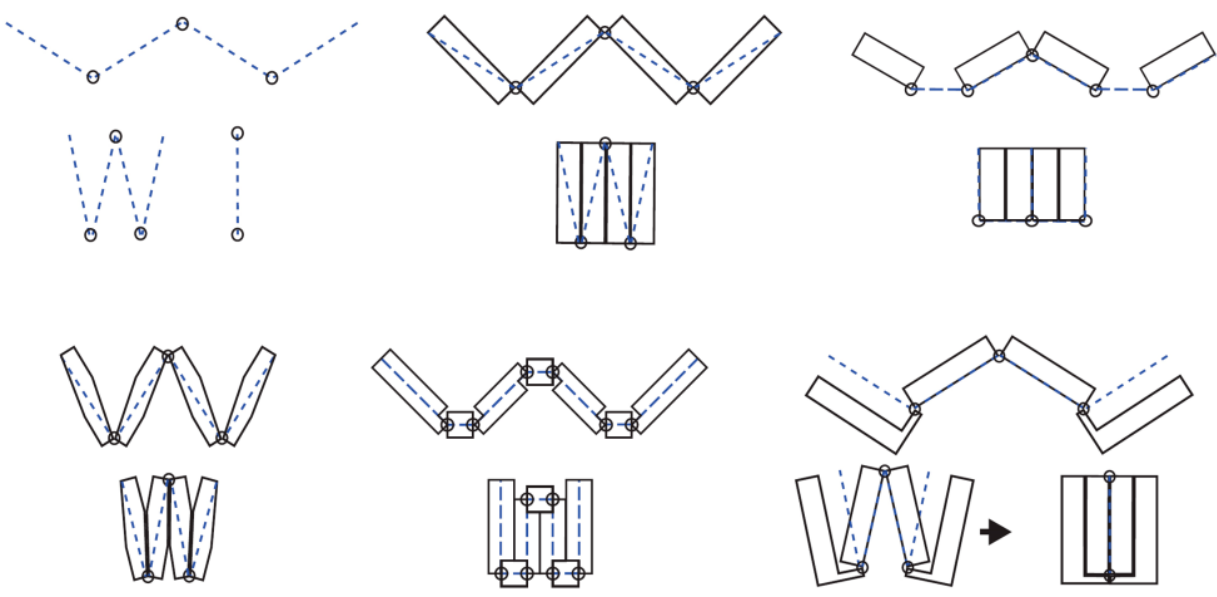

Figura 4: Adaptações dos vincos de papel para materiais rígidos. Fonte: Adaptado de Morgan et al. (2016).

Por conta das diversas possibilidades de adaptação dos vincos, se o origami possui apenas um DOF, será mais fácil sua aplicação e preservação cinemática. Em termos de comparação, uma mão humana possui vinte e dois DOFs desde o pulso até a ponta dos dedos, daí a complexidade de se projetar uma prótese que atenda os mesmos tipos de movimentos e execução de tarefas que uma mão pode realizar. O quarto critério de escolha é a vantagem mecânica, ou seja, eleger qual modelo de papel demanda menos força exercida para se abrir ou se fechar e, assim, evitar desgaste da própria ferramenta e fadiga por parte da(o) cirurgiã(o). Diferente dos demais critérios, que podem ser aplicados metodologicamente em vários tipos de design de origami para produtos em geral, os últimos dois critérios são mais voltados ao fórceps em si. O quinto critério é a relação entre a superfície da garra e o tamanho da ferramenta, ou seja, uma eleição da melhor forma que abarque maior superfície para agarrar mais material cirúrgico e no menor tamanho possível, para continuar atendendo a funcionalidade de procedimento minimamente invasivo. O sexto e último critério é a amplitude do movimento, uma complementação do quinto critério, buscando um modelo que abarque maior abrangência de abertura da pinça para diminuir as restrições de movimentos dentro do corpo da(o) paciente. O protótipo inicial do Oriceps foi fabricado com policarbonato e Delrin ${ }^{\circledR}$, um tipo de resina de acetal que substitui metais e plásticos de engenharia. Porém, esses materiais foram substituídos posteriormente porque apresentaram muita rigidez que comprometia a deformação das dobras. O segundo protótipo foi fabricado com vidro metálico, material que permitiu alta força de rendimento com movimento controlado e sem deformação plástica. Além do vidro metálico, os pesquisadores também recomendaram o uso de materiais inteligentes como as ligas de memória de forma (que também atende pela sigla LMF), cerâmicas e polímeros que apresentam a característica de retornarem ao estado inicial planificado através de estímulos como o calor. A fabricação foi realizada em uma cortadora a laser, mas em estudo mais recente os pesquisadores chegaram a produzir o Oriceps por impressora 3D também (NELSON et al., 2016). 
Com a execução dos protótipos, o Oriceps apresentou as mesmas funcionalidades de um instrumental cirúrgico tradicional, mas com a considerável melhoria de ser uma peça única e que pode voltar ao estado planificado para transporte, higienização e armazenamento sem prejudicar sua estrutura ou sua funcionalidade. As principais vantagens de inovação e sustentabilidade proporcionadas pela adoção do design de origami na concepção de um novo fórceps são de duas ordens: os testes em formas e o resultado do produto. Para os testes de formas, os modelos de papel são baratos, acessíveis e fáceis de serem produzidos, possibilitando a produção de muitos tipos de formatos e mecânicas de dobras para serem testados e comparados entre si na ordem de eleger os que melhor atendam aos critérios do projeto. No resultado do produto, houve uma eliminação da manufatura de juntas e parafusos e, com isso, um corte de custos em montagem e economia de matéria-prima. Aos desafios que o design para instrumentos cirúrgicos abarca soma-se a dificuldade de escalabilidade de peças muito pequenas - esse fator restringe possibilidades de maquinários e processos de fabricação que consigam alcançar o nível de precisão do tamanho do objeto, o formato necessário e a montagem. Nesse sentido o Oriceps demonstrou ter design simplificado, tornando fácil sua fabricação em pequenas escalas.

\section{Stent Cardíaco adaptado do origami}

Um modelo de dobradura muito utilizada em design para a área médica é o Waterbomb (ou em japonês fusen no kihonkei 風船の基本形), um origami tipo tesselação (tessellation em inglês), isto é, uma dobradura que possui repetidos padrões geométricos no papel (GJERDE, 2008) e que possui coeficiente de Poisson negativo (TURNER; GOODWINE; SEN, 2016). Materiais com o coeficiente de Poisson negativo, também conhecidos como auxéticos ou antiborrachas expandem-se quando tracionados e contraem-se quando comprimidos.
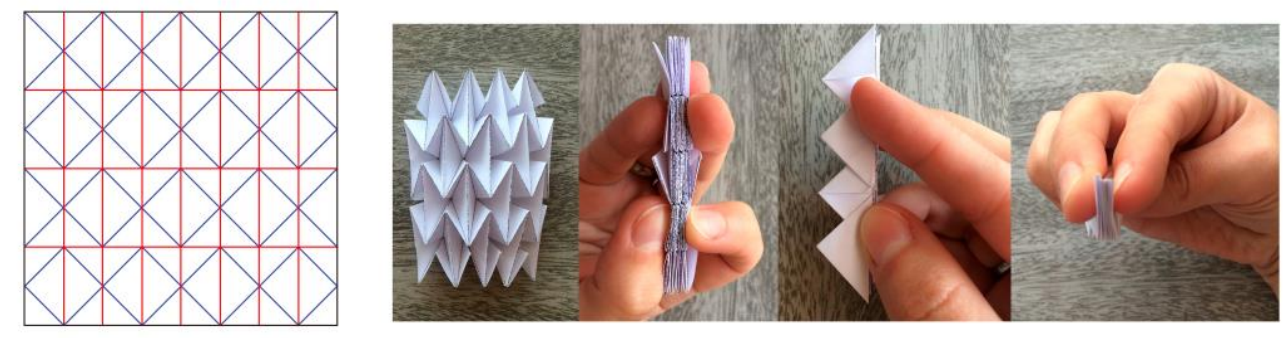

Figura 5: Origami do tipo tesselação Waterbomb. Fonte: Elaborada pelos autores.

O comportamento auxético proporcionado pelo Waterbomb foi aproveitado para implementação de um design de stent cardíaco (KURIBAYASHI et al., 2006). Stent cardíaco é uma endoprótese (do inglês stent graft), um tipo de dispositivo flexível e em formato de tubo capaz de ser dobrado e encaixado em pequenos espaços, muito comumente utilizado em cirurgias minimamente invasivas. As endopróteses possuem a função de ou desbloquear lúmens (cavidades do corpo humano como artérias e intestino) que estão entupidos ou proteger lúmens enfraquecidos, sendo utilizadas em estenoses arteriais - um tipo de estreitamento anormal de um vaso sanguíneo; aneurismas na aorta - uma dilatação anormal causada pelo enfraquecimento das paredes do vaso devido a um trauma por doença vascular; e cânceres de esôfago. Ao contrário 
dos stents convencionais que são feitos de uma malha de arames juntamente com uma membrana de cobertura, o stent adaptado do origami foi projetado a partir de uma única folha de liga NiTi (níquel e titânio), uma liga de memória de forma - LMF estruturada apenas com dobras-vales e dobras-montanhas, o que representa uma melhoria de design em termos de economia de materiais e simplicidade nas etapas de fabricação. O padrão de dobras foi feito por gravura fotoquímica negativa. A abertura do stent é feita pelo efeito da LMF em contato com a temperatura do corpo ou pelo uso de propriedade de superelasticidade. Os protótipos do stent com design de origami possuem o mesmo tamanho das endopróteses padronizadas e foram aplicadas no esôfago e na aorta durante o processo cirúrgico da angioplastia. Suas aberturas foram realizadas conforme o esperado, o que garantiu segurança nos testes realizados e viabilizando a produção do stent no mercado.

\section{Músculos artificiais com estrutura em origami}

Uma série de diferentes tipos de músculos artificiais estão sendo desenvolvidos atualmente com especificidades de aplicações em produtos e serviços variados dentro do design de robôs, dispositivos vestíveis (ou wearables) e próteses humanas. Uma das inovações tecnológicas desse tipo de design é o uso massivo e variado de materiais inteligentes, isto é, materiais que são capazes de sentir mudanças no ambiente em que estão inseridos e de responderem a esses estímulos de uma forma predeterminada (CALLISTER JUNIOR; RETHWISCH, 2010). Outra inovação também está presente na criação e uso de atuadores, quer dizer, sistemas eletrônicos complexos ou simples que podem controlar a forma e/ou deslocamento de um objeto remotamente por eletricidade, variação de temperatura, magnetismo, entre outros, como foi utilizado na montagem e desmontagem da pinça Oriceps e na abertura do stent cardíaco de origami.

De acordo com Li et al. (2017), dentro do design de músculos artificiais existem alguns atuadores mais utilizados, cada um com modus operandi específico e com restrições que valem ser citados: as já citadas LMFs ou SMAs (em inglês shape-memory alloys), ligas de memória de forma que possuem deformação reversível conforme a variação de temperatura, mas que também possuem ciclos de estímulos e respostas relativamente lentos em comparação a outros tipos de atuadores; os VAMPs (em inglês vacuum-actuated muscle-inspired pneumatic structures), estruturas pneumáticas ativadas a vácuo que possuem limitações de atuação e contração por conta do seu tipo de acionamento - a flambagem elastomérica e a pressão negativa do vácuo; e os EAPs (em inglês electroactive polymers), polímeros eletroativos do tipo iônicos ou dielétricos e tendo a necessidade de tensões muito altas para se deformarem, o que pode dificultar a praticidade de aplicação. Depois dos materiais inteligentes e atuadores, inovações em design de músculos artificiais giram em torno também das possibilidades de formas associadas, e nesse sentido o design de origami possui relevância. Para entender melhor como se dão as vantagens da adaptação do origami no design de músculos artificiais, são analisados dois estudos.

Depois do stent cardíaco, o padrão de dobras Waterbomb foi aplicado também em um músculo artificial robótico (ONAL; WOOD; RUS, 2013). De acordo com os pesquisadores, o 
design de robôs inspirados em origami introduz um novo método de fabricação mais rápido, com baixo custo, mais funcionalidades e que atende melhor as aplicações robóticas modernas. Onal, Wood e Rus (2013) apresentaram uma construção de sistema robótico que se autodobra, isto é, um robô de origami projetado a partir de uma folha plana que se transforma em um corpo complexo tridimensional apenas com dobras e atuação remota. A matéria-prima utilizada para a concepção do robô foi o polímero PEEK (poliéter-éter-cetona) e atuadores de bobina NiTi (níquel e titânio) e o processo de fabricação foi com uma máquina de corte a laser de $\mathrm{CO}_{2}$. $\mathrm{O}$ movimento foi bioinspirado nas minhocas que é o peristaltismo, possível de simular com o origami Waterbomb, e que possui a vantagem de ter uma locomoção robusta em espaços limitados. Outras vantagens desse design de origami é que o robô pode ser mantido desdobrado quando não estiver em uso, tendo menos problemas com armazenamento e transporte. Em comparação a estruturas sólidas típicas dos robôs como aço, alumínio e outros metais, a folha de polímero do músculo artificial de origami é muito mais leve, barata e acessível.

Depois dos SMAs, VAMPs e EAPs, Li et al. (2017) desenvolveram um novo tipo de atuador com design de origami: músculos artificiais acionados por fluidos, os FOAMs (em inglês fluiddriven origami-inspired artificial muscles). Quando comparado aos outros atuadores, os FOAMs possuem uma arquitetura estrutural em dobras que permitem a programação de movimentos multiaxiais controláveis em diferentes intensidades. De design simples e replicável facilmente, esse atuador foi composto por um esqueleto interno rígido, um fluido que o envolve e uma pele externa maleável. O esqueleto é uma superfície mais rígida que possui a adaptação em origami, sendo que a geometria de dobras determina o tipo de movimento do músculo. De acordo com os pesquisadores, o esqueleto pode ser fabricado por diversos tipos de processos como impressão 3D, corte a laser, moldagem em gesso, fundição, e até manualmente. $\mathrm{O}$ material varia de acordo com a necessidade de uso, podendo ser folhas de aço inoxidável, PEEK (poliéter-éter-cetona), silicone, PVA (acetato de polivinila), ou poliéster de vários tipos. $\mathrm{O}$ fluido interno que envolve o esqueleto possibilita o movimento automatizado e o controle de pressão exercida, podendo ser ar, água, ou outros tipos de líquidos.

A pele é a superfície externa maleável que serve para proteger os componentes internos e permite a locomoção programada pelo atuador; o material pode ser uma película polimérica como o TPU (poliuretano termoplástico), filme de PVC (policloreto de vinila), filme de PVA (acetato de polivinila) ou mesmo tecidos. O processo de funcionamento do FOAM acontece da seguinte forma: no início, o sistema está em repouso, com pressões interna e externa iguais; há uma abertura na pele que retira o fluido de dentro do músculo, fazendo com que a pressão interna seja maior que a externa. A diferença de pressão faz com que o músculo comece a se autocomprimir e deformar sua estrutura de acordo com a geometria de dobras do esqueleto. Em testes realizados, esse músculo artificial, apesar de leve, conseguiu levantar um pneu de vinte e dois quilos em trinta segundos. O design de origami do FOAM aumenta a abrangência de compactação e expansão estrutural que, aliado ao sistema de diferentes tipos de pressões internas e externas com fluidos, conferem ao atuador uma alta capacidade de trabalho.

Além do levantamento de cargas que pode ser utilizado em organizações de estoques de fábricas e manipulação de objetos marítimos, na área da saúde o design de origami adaptado para músculo artificial de Li et al. (2017) pode ser adotado em próteses parciais, completas e 
wearables, de maneira a contribuir na recuperação de movimentos do corpo que possuem alguma deficiência ou que sofreram acidentes, e a substituição de membros perdidos. As técnicas das dobraduras garantem ao atuador rapidez, eficiência energética, mas, especialmente, dinâmica de manufatura, podendo ser fabricado em múltiplas escalas e com uso variado de materiais acessíveis e a custos baixos. A variedade de processos fabris possíveis do FOAM facilita a implementação do projeto em diferentes países e orçamentos.

\section{Microrrobô de origami para problemas no estômago}

Um dos estudos de Miyashita et al. (2016) foi desenvolvido em cima de design de robô de origami voltado para procedimentos clínicos no trato gástrico. O microrrobô de origami é feito com uma folha biodegradável e biocompatível, armazenado dentro de uma cápsula de gelo para ser engolida, e que se automonta no robô dobrado quando chega ao estômago, podendo realizar diferentes ações como costurar uma ferida interna, remover corpos estranhos - como pilhas ou moedas engolidas por crianças, e entregar medicamentos. O controle é feito por meio de um sistema de atuação remoto e eletromagnético que possui quatro bobinas cilíndricas. A folha que compõem o corpo do robô é composta por cinco lâminas de materiais diferentes, entre eles a poliolefina (um tipo de termoplástico), parede de intestino de porco, um verniz próprio de medicamentos e solúvel em água, um filme termoencolhível (material que permite a autodobragem a $65^{\circ} \mathrm{C}$ ) e silicone, todos com propriedades biocompatíveis com o ser humano e biodegradáveis. A composição em diferentes camadas permite que o corpo de origami do robô se decomponha em diferentes momentos, viabilizando a função a ele designada, ou seja, é esperado que a camada do verniz de medicamento se decomponha mais rápido para liberar o ingrediente do medicamento, ao passo que é esperado que as camadas orgânicas se decomponham mais lentamente, pois fazem parte da estrutura robótica.

A aplicação da técnica do origami possui duas funcionalidades: compactação e estruturação. As dobras compactam o robô para entrar na cápsula, permitindo não apenas a ingestão segura dentro do corpo, como também a sua alocação em pequenos espaços, se necessário. As dobras possuem também a funcionalidade de pernas e braços para o robô, elas se estruturam de forma minimalista, porém efetiva, possibilitando movimentos de costura das feridas e deslocamento dentro do corpo. As vantagens do design de origami desse microrrobô para tratamentos no estômago estão na contribuição de intervenções clínicas minimamente invasivas, permitindo que a estrutura robótica se reconfigure para ocupar pequenos espaços ao mesmo tempo em que cumpre tarefas mecânicas versáteis apenas por controle remoto magnético externo. O microrrobô de origami é uma solução robótica inédita e alternativa aos medicamentos e cirurgias para problemas estomacais.

\section{Considerações Finais}

A aproximação mais ativa da pesquisa em design de origami na área médica é bastante recente e com muito a ser explorado ainda. O universo da medicina carrega uma grande série de 
protocolos, regulamentações e testes seriados que, ao mesmo tempo em que burocratizam a viabilidade de novas tecnologias para ter segurança garantida aos procedimentos clínicos, também dificultam a participação de terceiros dentro deste processo que não sejam médicos ou outros profissionais da saúde. Nesse sentido, os designers e pesquisadores em design possuem um importante papel como fomentadores de soluções de produtos e processos médicos mais seguros, eficazes, ergonômicos e benéficos à saúde humana. O presente artigo fez uma revisão e análise de pesquisas de design de origami aplicado à área médica, diferenciando a inspiração e a adaptação em dobras e com o intuito de compreender as características de algumas tecnologias, desde materiais, processos, formas, funções, e como as dobraduras podem contribuir para projetos multidisciplinares inovadores e sustentáveis. Foi visto que o design de origami na área da saúde está intimamente conectado a diversas tecnologias emergentes como os atuadores e os materiais inteligentes, abrindo um leque de novas possibilidades de se projetar e manipular instrumentais médicos, próteses e soluções robóticas para automatizar intervenções cirúrgicas e clínicas. Ao se aplicar padrões de dobras adaptados do origami nas estruturas dos produtos médicos, os procedimentos passam a ter vantagens a curto e longo prazo como tempo economizado em cirurgias minimamente invasivas, menor investimento de energia em compactação e expansão de ferramentas e, por consequência, diminuição do tempo de recuperação das(os) pacientes e os danos por fadiga para médicas(os). $\mathrm{O}$ design de origami também confere aos artefatos médicos maior eficácia de fabricação por sua metodologia pautada em peças monolíticas que se montam apenas com dobras, viabilizando a produção de instrumentos cada vez menores e invasivos, diminuindo custos com manufatura e montagem de peças sobressalentes, economizando espaço de transporte e armazenamento e aumentando a gama de diferentes tipos de matérias-primas aplicáveis.

\section{Agradecimento}

Apoio: processo nº 2018/21396-3, Fundação de Amparo à Pesquisa do Estado de São Paulo (FAPESP).

\section{Referências}

AVILA, A. et al. Origami fold states: Concept and design tool. Mechanical Sciences, v. 10, n. 1, p. 91-105, 2019. DOI 10.5194/ms-10-91-2019. Disponível em: https://www.mechsci.net/10/91/2019/. Acesso em: 13 jan. 2020.

BASSIK, N. et al. Enzymatically Triggered Actuation of Miniaturized Tools. Journal of the American Chemical Society, v. 132, n. 46, p. 16314-16317, 2010. DOI 10.1021/ja106218s. Disponível em: https://pubs.acs.org/doi/10.1021/ja106218s. Acesso em: 23 jul. 2020.

BECKER, M. Graus de Liberdade em Cadeias Cinemáticas. [S. I.: s. n.], 2014. Disponível em: https://docplayer.com.br/85078910-Sem-aula-2-graus-de-liberdade-emcadeias-cinematicas-prof-dr-marcelo-becker.html. Acesso em: 11 jun. 2020.

CALLISTER JUNIOR, W. D.; RETHWISCH, D. G. Materials Science and Engineering An Introduction. 8. ed. Danvers: John Wiley \& Sons, 2010. 
CHEN, Y. et al. Intra-cardiac MR imaging \& MR-tracking catheter for improved MR-guided EP. Journal of Cardiovascular Magnetic Resonance, v. 17, n. S1, p. 1-2, 2015. DOI 10.1186/1532-429x-17-s1-p237. Disponível em: https://jcmronline.biomedcentral.com/articles/10.1186/1532-429X-17-S1-P237. Acesso em: 23 jul. 2020.

CHEN, Y.; PENG, R.; YOU, Z. Origami of thick panels. Science, v. 349, n. 6246, p. 396400, 2015. DOI 10.1126/science.aab2870. Disponível em: https://science.sciencemag.org/content/349/6246/396. Acesso em: 21 jul. 2020.

DUREISSEIX, D. An overview of mechanisms and patterns with origami. International Journal of Space Structures, v. 27, n. 1, p. 1-14, 2012. DOI 10.1260/0266-3511.27.1.1. Disponível em: https://journals.sagepub.com/doi/10.1260/0266-3511.27.1.1. Acesso em: 23 jul. 2020.

EDMONDSON, B. J. et al. Oriceps: Origami-Inspired Forceps. Proceedings of the ASME 2013 Conference on Smart Materials, Adaptive Structures and Intelligent Systems. Anais...Snowbird: The American Society of Mechanical Engineers, 2013. DOI https://asmedigitalcollection.asme.org/SMASIS/proceedingsabstract/SMASIS2013/56031/V001T01 A027/284047. Acesso em: 21 jul. 2020.

FRANCIS, K. C. et al. From crease pattern to product: considerations to engineering origami-adapted designs. Proceedings of ASME 2014 International Design Engineering Technical Conferences \& Computers and Information in Engineering Conference. Anais...Buffalo: The American Society of Mechanical Engineers, 2014. Disponível em: http://proceedings.asmedigitalcollection.asme.org/proceeding. aspx ?articleid=2090926.

Acesso em: 21 jul. 2020.

GJERDE, E. Origami Tessellations: Awe-Inspiring Geometric Designs. Massachusetts: Taylor \& Francis Inc, 2008.

GREENBERG, H. C. et al. Identifying links between origami and compliant mechanisms. Mechanical Sciences, v. 2, n. 2, p. 217-225, 2011. DOI 10.5194/ms-2-217-2011. Disponível em: https://ms.copernicus.org/articles/2/217/2011/ms-2-217-2011.html. Acesso em: 23 jul. 2020 .

IWAKI, M. et al. A programmable DNA origami nanospring that reveals force-induced adjacent binding of myosin VI heads. Nature Communications, v. 7, p. 1-10, 2016. DOI 10.1038/ncomms13715. Disponível em: http://dx.doi.org/10.1038/ncomms13715. Acesso em: 23 jul. 2020.

JOHNSON, M. et al. Fabricating biomedical origami: a state-of-the-art review. International Journal of Computer Assisted Radiology and Surgery, v. 12, n. 11, p. 2023-2032, 2017. DOI 10.1007/s11548-017-1545-1. Disponível em: https://link.springer.com/article/10.1007/s11548-017-1545-1. Acesso em: 23 jul. 2020.

KURIBAYASHI, K. et al. Self-deployable origami stent grafts as a biomedical application of Ni-rich TiNi shape memory alloy foil. Materials Science and Engineering A, v. 419, p. 131-137, 2006. DOI 10.1016/j.msea.2005.12.016. Disponível em: https://www.sciencedirect.com/science/article/pii/S0921509305014930. Acesso em: 23 jul. 2020.

KUZUYA, A. et al. Nanomechanical DNA origami "single-molecule beacons" directly imaged by atomic force microscopy. Nature Communications, v. 2, n. 1, p. 448-449, 2011. DOI 10.1038/ncomms1452. Disponível em: http://dx.doi.org/10.1038/ncomms1452. Acesso em: 23 jul. 2020.

LI, S. et al. Fluid-driven origami-inspired artificial muscles. Proceedings of the National Academy of Sciences of the United States of America, v. 114, n. 50, p. 13132-13137, 
2017

DOI

10.1073/pnas.1713450114.

Disponível

em:

https://www.pnas.org/content/114/50/13132. Acesso em: 23 jul. 2020.

MEHNER, P. J. et al. Toward engineering biological tissues by directed assembly and origami folding. American Mathematical Society AMS Non-Series Monographs, v. 95.2, p. 545-555, 2015. DOI 10.1090/mbk/095.2/17. Disponível em: https://pdfs.semanticscholar.org/91ad/7666ddc2ac91c076fe9c130b51549f2ff17f.pdf. Acesso em: 23 jul. 2020.

MERALI, Z. "Origami engineer" flexes to create stronger, more agile materials. Science, v. 332, n. 6036, p. 1376-1377, 2011. DOI 10.1126/science.332.6036.1376. Disponível em: https://science.sciencemag.org/content/332/6036/1376/tab-article-info. Acesso em: 23 jul. 2020.

MIYASHITA, S. et al. Self-folding miniature elastic electric devices. Smart Materials and Structures, v. 23, n. 9, 2014. DOI 10.1088/0964-1726/23/9/094005. Disponível em: https://iopscience.iop.org/article/10.1088/0964-1726/23/9/094005/meta. Acesso em: 23 jul. 2020.

MIYASHITA, S. et al. An Untethered Miniature Origami Robot that Self-folds, Walks, Swims, and Degrades. IEEE International Conference on Robotics and Automation (ICRA). Anais...Seattle: Institute of Electrical and Electronics Engineers (IEEE), 2015 DOI 10.1109/ICRA.2015.7139386. Disponível

em: https://ieeexplore.ieee.org/document/7139386. Acesso em: 23 jul. 2020.

MIYASHITA, S. et al. Ingestible, controllable, and degradable origami robot for patching stomach wounds. Proceedings - IEEE International Conference on Robotics and Automation (ICRA). Anais...Estocolmo: IEEE Institute of Electrical and Electronics Engineers, 2016. DOI 10.1109/ICRA.2016.7487222. Disponível em: https://ieeexplore.ieee.org/document/7487222. Acesso em: 23 jul. 2020.

MORGAN, M. R. et al. Towards developing product applications of thick origami using the offset panel technique. Mechanical Sciences, v. 7, n. 1, p. 69-77, 2016. DOI 10.5194/ms-769-2016. Disponível em: https://ms.copernicus.org/articles/7/69/2016/. Acesso em: 23 jul. 2020.

NELSON, T. G. et al. Facilitating deployable mechanisms and structures via developable lamina emergent arrays. Journal of Mechanisms and Robotics, v. 8, n. 3, 2016. DOI $10.1115 / 1.4031901$ Disponível em: https://asmedigitalcollection.asme.org/mechanismsrobotics/articleabstract/8/3/031006/441834/Facilitating-Deployable-Mechanisms-andStructures?redirectedFrom=fulltext. Acesso em: 23 jul. 2020.

ONAL, C. D.; WOOD, R. J.; RUS, D. An Origami-Inspired Approach to Worm Robots. IEEE/ASME Transactions on Mechatronics, v. 18, n. 2, p. 430-438, 2013. DOI 10.1109/TMECH.2012.2210239. Disponível

em: https://ieeexplore.ieee.org/document/6266749. Acesso em: 23 jul. 2020.

ROTHEMUND, P. W. K. Folding DNA to create nanoscale shapes and patterns. Nature, v. 440, n. 7082, p. 297-302, 2006. DOI 10.1038/nature04586. Disponível em: https://www.nature.com/articles/nature04586. Acesso em: 23 jul. 2020.

SCHMIDT, E. J. et al. Intra-Cardiac MRI Catheter for EP Ablation Monitoring: Preliminary Studies. Proceedings of the 19th annual meeting of International Society for Magnetic Resonance in Medicine (ISMRM). Anais...Montreal: 2011. Disponível em: https://cds.ismrm.org/protected/11MProceedings/files/3741.pdf. Acesso em: 23 jul. 2020.

TAYLOR, A. et al. Intracardiac magnetic resonance imaging catheter with origami deployable mechanisms. Journal of Medical Devices, v. 10, n. 2, p. 2-3, 2016. DOI $10.1115 / 1.4033151$. 
https://augusta.pure.elsevier.com/en/publications/intracardiac-magnetic-resonance-imagingcatheter-with-origami-dep. Acesso em: 23 jul. 2020.

TURNER, N.; GOODWINE, B.; SEN, M. A review of origami applications in mechanical engineering. Proceedings of the Institution of Mechanical Engineers, Part C: Journal of Mechanical Engineering Science, v. 230, n. 14, p. 2345-2362, 2016. DOI 10.1177/0954406215597713. Disponível em: https://journals.sagepub.com/doi/10.1177/0954406215597713. Acesso em: 23 jul. 2020.

VENEZIANO, R. et al. Role of nanoscale antigen organization on B-cell activation probed using DNA origami. Nature Nanotechnology, p. 2020.02.16.951475, 2020. DOI 10.1038/s41565-020-0719-0. Disponível em: https://www.nature.com/articles/s41565-0200719-0. Acesso em: 23 jul. 2020.

YAMADA, T. R. U. Estruturas flat foldable em Bambu Laminado Colado baseadas em técnicas de dobra e corte do origami e do kirigami. 2016. 224p. Tese (Doutorado em Design) - Universidade Estadual Paulista, Bauru, 2016.

ZHAO, R. et al. Kirigami enhances film adhesion. Soft Matter, v. 14, n. 13, p. 2515-2525, 2018. DOI 10.1039/c7sm02338c. Disponível em: http://dx.doi.org/10.1039/c7sm02338c. Acesso em: 23 jul. 2020.

ZHU, S.; LI, T. Hydrogenation-Assisted Graphene Origami and Its Application in Programmable Molecular Mass Uptake, Storage, and Release. ACS Nano, v. 8, n. 3, p. 2864-2872, 2014. DOI 10.1021/nn500025t. Disponível em: https://pubs.acs.org/doi/10.1021/nn500025t. Acesso em: 23 jul. 2020.

\section{Sobre os autores}

\section{Samanta Aline Teixeira}

Doutoranda pelo Programa de Pós-graduação em Design da UNESP - Universidade Estadual Paulista. Possui mestrado em Design, no mesmo programa e graduação em Design com habilitação em Design Gráfico pela UNESP. Área de atuação: Design de origami aplicado a instrumentais médicos.

ORCID https://orcid.org/0000-0001-5308-5018

\section{Galdenoro Botura Junior}

Doutor em Engenharia Elétrica pela UNICAMP. Livre docente pela UNESP - Universidade Estadual Paulista. Especialista em gestão e liderança universitária pela Organização Universitária Interamericana, no Canadá. Área de atuação: Inovação Tecnológica e sua interação com o Design.

ORCID https://orcid.org/0000-0002-5680-6017

\section{Thaís Regina Ueno Yamada}

Doutora em Design pela UNESP - Universidade Estadual Paulista. Atualmente, é Professora Assistente Doutora do Departamento de Artes e Representação Gráfica da FAAC - UNESP, atuando nos cursos de Design, Matemática e Artes Visuais. Área de atuação: Expressão gráfica e aplicações de técnicas do origami e kirigami em projetos de Design.

ORCID https://orcid.org/0000-0002-0112-8845 